\title{
Editorial
}

\section{Welcome to Antibodies: A New Open Access, Multidisciplinary Journal}

\section{Tomohiro Kurosaki ${ }^{1,2}$}

1 Laboratory of Lymphocyte Differentiation, WPI Immunology Frontier Research Center, Osaka University, Suita 565-0871, Japan; E-Mail: kurosaki@ifrec.osaka-u.ac.jp;

Tel.: +81-6-6879-4456

2 Laboratory for Lymphocyte Differentiation, RIKEN RCAI, Yokohama 230-0045, Japan

Received: 15 December 2011 / Accepted: 23 December 2011 / Published: 30 December 2011

Secreted antibodies are a key player for exerting appropriate humoral immunity. For instance, in infectious diseases, poly-specific "natural" antibodies provide early protection, independent of $\mathrm{T}$ cell help. If this line of defense is crossed, $\mathrm{T}$ cell-dependent immune responses then generate a humoral memory provided by long-lived plasma cells secreting specific antibodies of adapted avidity and isotype. Secreted antibodies provide an efficient line of defense against re-infection and are backed up by specific memory B and $\mathrm{T}$ cells. In the field of humoral immunity, great discoveries including identification of a special $\mathrm{T}$ cell subset helping $\mathrm{B}$ cell activation $\left(\mathrm{T}_{\mathrm{FH}}\right)$, have been made in a last couple of years; however, important questions (such as mechanisms for affinity maturation of antibodies) still remain.

In addition to the above basic research aspects, antibodies have been well recognized as one of key therapeutic options for patients with a wide range of diseases. More than 25 antibodies are approved for human therapy and more than 240 antibodies are currently in clinical development worldwide for a wide range of diseases, including autoimmunity and inflammation, cancer, organ transplantation, and infectious diseases. Thus, antibodies are the most advanced bio-molecules for applying to treatment of patients. Therefore, I think that it will be challenging to make feed-back-forward loops between outcomes from basic research, development to new generation of therapeutic antibodies, and clinical outcomes. I expect Antibodies to become a venue for the rapid and affordable publication of both basic and clinical manuscripts in the field of humoral immunity, thereby further enhancing the tight connection between bench side and bed side.

(C) 2012 by the authors; licensee MDPI, Basel, Switzerland. This article is an open access article distributed under the terms and conditions of the Creative Commons Attribution license (http://creativecommons.org/licenses/by/3.0/). 